\title{
Optimal Management of a Virtual Power Plant
}

\author{
Dan Jigoria-Oprea, Gheorghe Vuc, Marcela Litcanu
}

\begin{abstract}
Deregulation of energy market led to the development of flexible and efficient framework for energy trading by energy companies in a competitive environment. Both deregulation and the concern towards environment issues increased the number of small and medium renewable power plants distributed in the network. The variability of renewable energy sources and the lack of their central monitoring led to new challenges concerning power system operation. The idea of aggregation for distributed energy sources led to the concept of virtual power plant, which determines a better control of production units but also a better visibility for the system operator. In this paper, the authors propose an optimal management solution which can offer a virtual power plant the capability to sell complete services, both for production and demand side management, by decreasing the necessary reserve for balance.
\end{abstract}

Index Terms - energy market, optimal management, renewable energy sources, virtual power plant.

\section{INTRODUCTION}

$\mathrm{T}$ HE increased share of renewable energy sources in the electricity production brings issues concerning power balance in the power system. Generating electricity from renewable sources is influenced by weather conditions and by the availability of source - wind or sun. Using the power reserve of centralized sources is justified only form economic point of view. This reserve is used to compensate the shortage of energy determined by the unpredictable nature of renewable sources power generation. As a result, it seems more intelligent to transfer the balance load to another level of structure in the network. This structure should include different types of distributed resources, energy storage units and to have control and command rights.

All these can be combined in a structure like the virtual power plant (VPP) that can operate like a classical power plant. All operations for each unit can be programed in advance. The concept of VPP has already a history of over two decades, experimental projects being tested in several parts of the world [1-4].

For the Romanian Power System, using the VPP as a solution for the management of renewable energy is not applicable yet; the solution used now considers including the renewable energy

This manuscript was submitted on 29 July 2016 and accepted on 18 September 2016.

D. Jigoria-Oprea is with the Power Systems Department at Politehnica University Timisoara, V. Parvan 2 Blvd., Timisoara, Timis, 300223, Romania (e-mail: dan.jigoria@upt.ro). sources (RES) in a large and diverse portfolio of a strong actor on the energy market.

\section{MATHEMATIC MODEL}

The optimization problem is actually a problem of maximizing the profit of the VPP [5], [6]. The aim is to maximize the profit for each and every one of the 24 hours:

profit $=\sum_{r=1}^{24}\left(\lambda_{t}^{I S O} \cdot\right.$ Bid $_{t}+\lambda_{t}^{D R} \cdot R_{t}+\lambda_{t}^{V P P} \cdot D_{t}-E_{t}^{D i s p}-y_{t} \cdot$ Start $)$

with constrains concerning:

- limits of the dispatchable generator:

$E_{t}^{\text {Disp }}=a \cdot x_{t}+b \cdot G_{t}+c \cdot G_{t}^{2}$

$x_{t} \cdot G^{\min } \leq G_{t} \leq x_{t} \cdot G^{\max }$

$-\operatorname{Ramp} \leq G_{t}-G_{t-1} \leq$ Ramp

$x_{t}-x_{t-1} \leq y_{t}$

- energy balance equation:

$G_{t}+W_{t}+S_{t} \leq D_{t}+B i d_{t}$

- constrains concerning energy delivery:

$\sum_{t=1}^{24} D_{t}=\sum_{t=1}^{24}\left(L_{i t}-R_{i t}\right)$

$D_{t} \geq 0.9 \cdot \sum_{t=1}^{N}\left(L_{i t}-R_{i t}\right)$

$D_{t} \leq 1.1 \cdot \sum_{t=1}^{N}\left(L_{i t}-R_{i t}\right)$

- demand response (DR) constrains:

G. Vuc is with the Power Systems Department at Politehnica University Timisoara, V. Parvan 2 Blvd., Timisoara, Timis, 300223, Romania (e-mail: gheorghe.vuc@upt.ro).

M. Litcanu was with Politehnica University Timisoara. She is now with QMB ENERG SRL, Eduard Benes 6, Timisoara, Timis, Romania (e-mail: marcela.litcanu@upt.ro). 


$$
\begin{aligned}
& R_{i t}=L_{i t} \cdot\left(1-\exp \left(-\alpha_{i t} \cdot\left(\lambda_{t}^{D R}-\lambda_{t}^{V P P}\right)\right)\right) \\
& \lambda_{t}^{V P P} \leq \lambda_{t}^{D R} \leq \lambda_{t}^{I S O} \\
& \sum_{t=1}^{24} R_{i t}>R^{\min }
\end{aligned}
$$

where:

$$
\lambda_{t}^{I S O} \text { - forecasted price on the day-ahead market in the } t
$$
period $(€ / \mathrm{MWh} / \mathrm{h})$;

$\lambda_{t}^{V P P}-$ contracted price inside the VPP during $t$ period $(€ / \mathrm{MWh} / \mathrm{h})$;

$G^{\max }$ - maximum production of dispatchable generator (MW);

$G^{\text {min }}$ - minimum production of dispatchable generator (MW);

Ramp - maximum ramp rate of the dispatchable generator (MW/min);

Start-dispatchable generator starting costs $(€)$;

$W_{t}$ - forecasted wind production for $t$ period (MW);

$S_{t}$ - forecasted PV production for $t$ period (MW);

$L_{i t}$ - forecasted load for consumer $i$ for $t$ period (MW);

$D_{t}-$ forecasted demand for $t$ period (MW);

$\alpha_{i t}$ - elasticity price factor for consumer $i$ in $t$ period;

$R^{\min }-$ minimum acceptable level for total load reduction (MW);

$E_{t}^{\text {Disp }}$ - generation costs for dispatchable generator during $t$ period (€/MWh/h);

$G t$ - output of the dispatchable generator during $t$ period (MW);

$\lambda_{t}^{D R}-$ price for demand side reduction during $t$ period $(€ / \mathrm{MW})$;

Profit - corresponding profit considering demand side reduction $(€)$;

$R_{i t}$ - forecasted load reduction for consumer $i$ during $t$ period (MW);

$B i d_{t}$ - hourly bid on energy market during $t$ period (MW);

$x_{t}$ - binary variable that indicate the state (operational/shutdown) of the dispatchable generator during $t$ period;

$y_{t}$ - binary variable that indicate if the dispatchable generator started during $t$ period.

The objective function takes into consideration the VPP offers on the market, which can be positive or negative. Domestic consumers pay a fixed price according to bilateral agreements, $\lambda_{t}^{V P P}$ equal to the levelized cost of energy (LCOE).

The constrains for the dispatchable generator (2-5) include the square cost function (2), minimum and maximum generation levels (3), ramp up/down limits (4) and starting elements (5). The energy balance constraint (6) imposes the balance between the dispatchable generator production, the renewable sources production and consumption. An excess of generated power or stored energy gives the sign of the demand side on the market. The energy delivery constrains grant the necessary power covering all the demand. Some deviations, positive or negative, are included in (8) and (9). Also, for the delivery constrains, the demand reduction using DR are subtracted from the entire demand quantity. This model also presents the minimum aggregated demand reduction which can be accepted by the VPP (12). The reductions are not accepted when the entire quantity is smaller than the minimum acceptable level.

\section{CASE STUDIES}

All the presented case studies were conducted considering the entire Romanian Power System as a VPP, more exactly like a Bulk VPP (BVPP) [7], but with an arbitrary separation of each constituents of the VPP, in order to test and use all the integrated facilities of the OptiMaCEV application [6], including individual influence of each member of the BVPP.

The objective of the case studies was minimizing the financial losses (13) of the BVPP on the balancing market during 24 hours, losses which are determined by the errors between forecasted values for generation and real values of energy generation, errors which cannot be compensated by the DR.

$$
\text { FLoss }=\sum_{t=1}^{24}\left(\Delta W_{\text {prod }}-\Delta W_{\text {cons }}\right)_{t} \cdot \Delta \lambda_{t}^{B M}
$$

where:

$\Delta \lambda_{t}^{B M}$ is the difference of energy price between the balancing market and day-ahead market during $t$ period $(€ / \mathrm{MW})$;

$\Delta W_{\text {prod }}$ - deviation of real energy production from forecasted value;

$\Delta W_{\text {cons }}$ - deviation of real energy consumption from forecasted value.

Several case studies were conducted for different characteristic days, from different seasons and with different structure of the history used for the forecast. The first case study is based on history data from 25-30 August 2014 and the focus day is 31 august. The second case study uses data from 5, 12, 19, 26 June, 3, 10 and 17 July and the focus day is 24 July.

All the case studies are using real data from 2014 in order to compare the forecast results to real evolution of consumption and generation for each considered source. Meanwhile, real market prices were used, both from the day-ahead market and balancing market. Values for load category elasticity factors were used from literature. The data used to model the VPP were obtained from the Romanian Transmission System Operator Transelectrica [8]. To compute the deviations of the forecast for 
each VPP component and the VPP imbalance, the real value of the consumption was used. The computation relations are:

$$
\begin{aligned}
& A b=\frac{V_{\text {prod }}-V_{\text {real }}}{W_{\text {cons_real }}} \cdot 100[\%] \\
& D e z=\frac{\Delta W_{\text {prod }}-\Delta W_{\text {cons }}}{W_{\text {cons_real }}} \cdot 100[\%]
\end{aligned}
$$

where:

$A b$ - corresponding deviation for the considered value (consumption, classical power plant production, etc.);

$V_{\text {prog }}$ - forecasted value (consumption, classical generation, wind generation, PV generation, etc.);

$V_{\text {real }}$ - real value for the considered time period (consumption, classical generation, wind generation, etc.);

$W_{\text {cons_real }}$ - real consumption value;

Dez - value of unbalance for the VPP as the result of deviation of forecasted values from the real ones.

\section{RESUlts AND DiscUSSIONS}

\section{A. Case Study \#1}

The results of interest for the forecasted (focus) day (on hourly intervals) are presented in Table 1.

The results for Case Study \#1 show high values of deviation for all hourly intervals for the classical power plant generation $(22 \%)$, while for PV the values are practically null. This is due to the fact that the installed power in these plants is smaller compared to other energy sources (also see (14)).

For the consumption component of the VPP, the deviations values are big. It is important to be noted that by aggregating the generation and consumption components in the VPP, the deviations per component are compensated and for all the VPP the maximum value of deviation is $21 \%$ and only for a few hourly intervals.

Another fact to note is that for 1 to 8 hour interval, the positive deviation of VPP is a "consumption excess" type and requires a reaction to decrease the value of the load. To minimize the unbalances of VPP, the $\mathrm{R}$ reaction of demand reduction (completely or partially), is used as necessary. Reducing the value of the unbalances have a positive influence for the VPP profit due to the fact that any unbalance must be covered using the balancing market, where prices are least favorable than on the day-ahead market.

The unbalance on VPP can reach the value 0 after considering the demand response for hourly interval 9, 11 and 16 to 20 , because the demand response was greater or at least equal with the necessary needed to bring the unbalance to 0 .

TABLE I

\begin{tabular}{|c|c|c|c|c|c|c|c|c|c|}
\hline $\begin{array}{l}\text { Hourly } \\
\text { Interval }\end{array}$ & $\begin{array}{c}\text { Classical } \\
\text { Power Plant } \\
\text { Deviation }\end{array}$ & $\begin{array}{c}\text { Wind } \\
\text { Deviation }\end{array}$ & $\begin{array}{c}\mathrm{PV} \\
\text { Deviation }\end{array}$ & $\begin{array}{l}\text { Consumption } \\
\text { Deviation }\end{array}$ & $\begin{array}{c}\text { Unbalance } \\
\text { VPP }\end{array}$ & $\lambda^{\mathrm{DR}}$ & $\mathrm{R}$ & $\lambda^{\mathrm{ISO}}$ & $\begin{array}{c}\text { Unbalance VPP } \\
\text { with DR }\end{array}$ \\
\hline 1 & $8.2 \%$ & $13.3 \%$ & $0.0 \%$ & $3.7 \%$ & $17.8 \%$ & 141.30 & 370.00 & 179.00 & $10.5 \%$ \\
\hline 2 & $11.8 \%$ & $15.8 \%$ & $0.0 \%$ & $7.8 \%$ & $19.7 \%$ & 140.80 & 360.00 & 178.00 & $12.2 \%$ \\
\hline 3 & $9.8 \%$ & $17.1 \%$ & $0.0 \%$ & $5.7 \%$ & $21.2 \%$ & 138.90 & 326.00 & 174.00 & $14.3 \%$ \\
\hline 4 & $12.2 \%$ & $15.3 \%$ & $0.0 \%$ & $10.3 \%$ & $17.2 \%$ & 130.70 & 257.50 & 157.00 & $11.7 \%$ \\
\hline 5 & $12.7 \%$ & $11.8 \%$ & $0.0 \%$ & $10.3 \%$ & $14.2 \%$ & 129.20 & 243.50 & 154.00 & $9.0 \%$ \\
\hline 6 & $12.0 \%$ & $10.7 \%$ & $0.0 \%$ & $9.6 \%$ & $13.1 \%$ & 126.30 & 211.30 & 148.00 & $8.5 \%$ \\
\hline 7 & $18.0 \%$ & $10.5 \%$ & $0.0 \%$ & $18.6 \%$ & $9.8 \%$ & 126.30 & 224.30 & 148.00 & $4.9 \%$ \\
\hline 8 & $8.2 \%$ & $6.6 \%$ & $-0.1 \%$ & $8.0 \%$ & $6.6 \%$ & 126.80 & 249.70 & 149.00 & $2.0 \%$ \\
\hline 9 & $20.6 \%$ & $5.5 \%$ & $-0.6 \%$ & $24.8 \%$ & $0.7 \%$ & 130.70 & 305.40 & 157.00 & $0.0 \%$ \\
\hline 10 & $22.6 \%$ & $6.0 \%$ & $-0.6 \%$ & $30.4 \%$ & $-2.4 \%$ & 95.00 & 60.70 & 174.00 & $-2.4 \%$ \\
\hline 11 & $21.5 \%$ & $7.4 \%$ & $-0.4 \%$ & $28.4 \%$ & $0.0 \%$ & 134.60 & 371.70 & 165.00 & $0.0 \%$ \\
\hline 12 & $20.0 \%$ & $6.1 \%$ & $0.0 \%$ & $28.0 \%$ & $-1.9 \%$ & 95.00 & 64.50 & 168.00 & $-1.9 \%$ \\
\hline 13 & $17.4 \%$ & $6.4 \%$ & $0.2 \%$ & $24.3 \%$ & $-0.3 \%$ & 95.00 & 63.00 & 157.00 & $-0.3 \%$ \\
\hline 14 & $19.7 \%$ & $6.9 \%$ & $0.2 \%$ & $28.3 \%$ & $-1.5 \%$ & 95.00 & 65.40 & 154.00 & $-1.5 \%$ \\
\hline 15 & $20.8 \%$ & $7.8 \%$ & $-0.2 \%$ & $29.7 \%$ & $-1.4 \%$ & 95.00 & 64.10 & 148.00 & $-1.4 \%$ \\
\hline 16 & $20.9 \%$ & $7.2 \%$ & $0.3 \%$ & $27.5 \%$ & $0.8 \%$ & 121.80 & 213.40 & 139.00 & $0.0 \%$ \\
\hline 17 & $17.6 \%$ & $7.9 \%$ & $-0.5 \%$ & $22.5 \%$ & $2.5 \%$ & 121.90 & 206.50 & 139.00 & $0.0 \%$ \\
\hline 18 & $2.8 \%$ & $5.7 \%$ & $-1.0 \%$ & $3.7 \%$ & $3.8 \%$ & 129.20 & 295.00 & 154.00 & $0.0 \%$ \\
\hline 19 & $17.4 \%$ & $6.6 \%$ & $0.3 \%$ & $22.4 \%$ & $1.9 \%$ & 134.60 & 367.60 & 165.00 & $0.0 \%$ \\
\hline 20 & $15.7 \%$ & $4.0 \%$ & $0.4 \%$ & $19.4 \%$ & $0.7 \%$ & 135.90 & 422.60 & 174.00 & $0.0 \%$ \\
\hline 21 & $12.6 \%$ & $2.4 \%$ & $0.1 \%$ & $17.6 \%$ & $-2.6 \%$ & 95.00 & 69.00 & 194.00 & $-2.6 \%$ \\
\hline 22 & $11.9 \%$ & $2.7 \%$ & $0.0 \%$ & $16.9 \%$ & $-2.4 \%$ & 95.00 & 70.30 & 229.00 & $-2.4 \%$ \\
\hline 23 & $10.9 \%$ & $2.3 \%$ & $0.0 \%$ & $14.9 \%$ & $-1.7 \%$ & 95.00 & 63.50 & 188.00 & $-1.7 \%$ \\
\hline 24 & $12.7 \%$ & $4.0 \%$ & $0.0 \%$ & $15.9 \%$ & $0.7 \%$ & 141.80 & 425.00 & 180.00 & $0.0 \%$ \\
\hline
\end{tabular}

VPP UNBALANCE FOR CASE STUDY \#1 WITHOUT AND WITH DR 
The balance price for the demand response, $\lambda^{D R}$ for intervals 10 and 21-23 is smaller than the internal energy price for consumption, $\lambda^{V P P}$, and signals the necessity to stimulate the growth of internal consumption to reduce the unbalance. For all occurrences, the demand response was used to reduce the unbalance.

Another thing that is noted is the negative value of the deviation of VPP unbalance for interval 10, 12-15 and 21-23. This is a "low consumption" type, which means that is necessary a demand response in order to increase the consumption, a signal given even by the demand response balance price.

Regarding minimizing the financial losses, from Table 2 it can be seen very clearly that using DR reduces supplementary costs determined by acquiring or selling energy to the balancing market during unbalance hourly intervals. The economy is about 844398.9 RON from 1448759.3 to 604360.4 RON.

The presented results also emphasize the fact that deviation of VPP when using demand response is the one who better attenuates the individual unbalance of their components.

TABLE II

DR INFLUENCE ON FinANCIAL LOSSES For CASE STUDY \#

\begin{tabular}{|c|c|c|c|c|c|c|c|c|c|c|c|}
\hline \multirow[t]{2}{*}{$\begin{array}{l}\text { Hourly } \\
\text { Interval }\end{array}$} & \multirow{2}{*}{$\begin{array}{c}\text { Unbalance } \\
\Delta \\
\text { witihout } \\
\text { DR } \\
{[\mathrm{MW}]}\end{array}$} & \multicolumn{2}{|c|}{$\begin{array}{l}\text { Unbalance Costs } \\
\text { [RON/MWh }]\end{array}$} & \multirow{2}{*}{$\begin{array}{c}\text { Supplementary } \\
\text { Cost }\end{array}$} & \multicolumn{2}{|c|}{$\begin{array}{c}\text { Unbalance influence } \\
\text { without DR }\end{array}$} & \multirow{2}{*}{$\begin{array}{c}\text { Unbalance } \\
\Delta \text { with } \\
\text { DR } \\
{[\mathrm{RON}]}\end{array}$} & \multirow{2}{*}{$\begin{array}{c}\text { DR } \\
{[\mathrm{MW}]} \\
\end{array}$} & \multirow{2}{*}{$\begin{array}{c}\begin{array}{c}\text { Supplementary } \\
\text { Cost }\end{array} \\
{[\mathrm{RON}}\end{array}$} & \multicolumn{2}{|c|}{$\begin{array}{c}\text { Unbalance influence } \\
\text { with DR }\end{array}$} \\
\hline & & Excess & Deficit & & [RON/MWh] & {$[\%]$} & & & & [RON/MWh] & {$[\%]$} \\
\hline 1 & -906.91 & 5.38 & 198.00 & 118450.91 & 23.25 & $14.5 \%$ & -536.91 & -370.00 & 83011.4 & 16.29 & $10.18 \%$ \\
\hline 2 & -950.73 & 39.57 & 243.49 & 92860.78 & 19.23 & $12.9 \%$ & -590.73 & -360.00 & 64643.4 & 13.39 & $8.98 \%$ \\
\hline 3 & -999.23 & 0.10 & 213.78 & 128521.93 & 27.30 & $18.3 \%$ & -673.23 & -326.00 & 100244.5 & 21.29 & $14.29 \%$ \\
\hline 4 & -801.29 & 0.10 & 214.62 & 64196.18 & 13.76 & $9.2 \%$ & -543.79 & -257.50 & 80970.0 & 17.35 & $11.64 \%$ \\
\hline 5 & -662.18 & 0.10 & 213.12 & 18747.80 & 4.01 & $2.7 \%$ & -418.68 & -243.50 & 63178.8 & 13.52 & $8.95 \%$ \\
\hline 6 & -605.25 & 0.10 & 221.68 & 1799.65 & 0.39 & $0.2 \%$ & -393.95 & -211.30 & 66927.6 & 14.45 & $8.50 \%$ \\
\hline 7 & -446.25 & 0.10 & 251.69 & 11680.67 & 2.57 & $1.3 \%$ & -221.95 & -224.30 & 44028.3 & 9.69 & $4.88 \%$ \\
\hline 8 & -360.72 & 0.10 & 258.83 & 14157.89 & 2.61 & $1.1 \%$ & -111.02 & -249.70 & 25412.0 & 4.68 & $2.04 \%$ \\
\hline 9 & -32.54 & 0.10 & 306.95 & 50763.69 & 10.38 & $4.1 \%$ & 0.00 & -32.54 & 0.0 & 0.00 & $0.00 \%$ \\
\hline 10 & 118.20 & 0.10 & 317.93 & 80914.05 & 16.38 & $7.0 \%$ & 118.20 & 0.00 & 9920.8 & 2.01 & $0.86 \%$ \\
\hline 11 & -2.37 & 0.10 & 310.29 & 63125.76 & 12.52 & $6.0 \%$ & 0.00 & -2.37 & 0.0 & 0.00 & $0.00 \%$ \\
\hline 12 & 97.05 & 0.10 & 290.83 & 54392.55 & 10.75 & $5.2 \%$ & 97.05 & 0.00 & 8233.2 & 1.63 & $0.79 \%$ \\
\hline 13 & 14.49 & 0.10 & 292.78 & 36625.46 & 7.19 & $3.5 \%$ & 14.49 & 0.00 & 1230.2 & 0.24 & $0.12 \%$ \\
\hline 14 & 76.41 & 0.10 & 304.85 & 58899.04 & 11.50 & $6.1 \%$ & 76.41 & 0.00 & 8852.5 & 1.73 & $0.91 \%$ \\
\hline 15 & 67.90 & 0.10 & 299.80 & 53363.86 & 10.65 & $5.6 \%$ & 67.90 & 0.00 & 7523.2 & 1.50 & $0.79 \%$ \\
\hline 16 & -42.38 & 0.10 & 281.81 & 31384.22 & 6.22 & $3.3 \%$ & 0.00 & -42.38 & 0.0 & 0.00 & $0.00 \%$ \\
\hline 17 & -127.81 & 0.10 & 278.55 & 19984.04 & 3.93 & $2.1 \%$ & 0.00 & -127.81 & 0.0 & 0.00 & $0.00 \%$ \\
\hline 18 & -229.42 & 0.10 & 278.07 & 20381.66 & 3.38 & $1.8 \%$ & 0.00 & -229.42 & 0.0 & 0.00 & $0.00 \%$ \\
\hline 19 & -101.35 & 0.10 & 260.70 & 61196.76 & 11.70 & $7.7 \%$ & 0.00 & -101.35 & 0.0 & 0.00 & $0.00 \%$ \\
\hline 20 & -36.50 & 0.10 & 255.97 & 58790.76 & 10.89 & $5.9 \%$ & 0.00 & -36.50 & 0.0 & 0.00 & $0.00 \%$ \\
\hline 21 & 150.53 & 0.10 & 259.25 & 91217.77 & 15.47 & $8.6 \%$ & 150.53 & 0.00 & 11929.4 & 2.02 & $1.12 \%$ \\
\hline 22 & 142.29 & 0.10 & 269.88 & 133859.31 & 22.16 & $14.9 \%$ & 142.29 & 0.00 & 17200.5 & 2.85 & $1.91 \%$ \\
\hline 23 & 94.73 & 0.10 & 235.70 & 106233.32 & 19.13 & $16.1 \%$ & 94.73 & 0.00 & 11054.5 & 1.99 & $1.67 \%$ \\
\hline 24 & -37.83 & 0.10 & 232.78 & 77211.25 & 14.95 & $12.6 \%$ & 0.00 & -37.83 & 0.0 & 0.00 & $0.00 \%$ \\
\hline
\end{tabular}

\section{B. Case Study \#2}

The results of interest for the forecasted (focus) day (on hourly intervals) are presented in Table 3.

The results for Case Study \#2 show deviation values smaller than $10 \%$ for the majority of hourly intervals, while for the PV the values are practically null.

For the consumption component of the VPP the deviation values are also smaller (with a maximum value of $14.6 \%$ ), the large values appearing only in three intervals. Again, by aggregating the generation and consumption components in the VPP, the deviations per component are compensated and for all the VPP the maximum value of deviation is $12 \%$ and only for a few hourly intervals.

The positive values for deviation during 3-7, 9-13 and 15-24 hourly intervals is a "consumption excess" type and requires a reaction to decrease the value of the load. To minimize the unbalances of VPP, the $R$ reaction of demand reduction (completely or partially), is used as necessary. Also for this case, reducing the value of the unbalances have a positive influence for the VPP profit due to the fact that any unbalance must be covered using the balancing market, where prices are least favorable than on the day-ahead market.

For interval 2, 8 and 14, using DR the unbalance can be eliminated (the final value of the unbalance is 0 ) due to DR contribution - its availability was greater or at least equal with the necessary value to compensate the unbalance.

For this case study, only for the first hourly interval the deviation has a negative value - low consumption unbalance. This signals the fact that an increase of consumption reaction is needed. 
TABLE III

VPP UNBALANCE FOR CASE STUDY \#2 WITHOUT AND WITH DR

\begin{tabular}{|c|c|c|c|c|c|c|c|c|c|}
\hline $\begin{array}{l}\text { Hourly } \\
\text { Interval }\end{array}$ & $\begin{array}{l}\text { Classical } \\
\text { Power Plant } \\
\text { Deviation }\end{array}$ & $\begin{array}{c}\text { Wind } \\
\text { Deviation }\end{array}$ & $\begin{array}{c}\text { PV } \\
\text { Deviation }\end{array}$ & $\begin{array}{c}\text { Consumption } \\
\text { Deviation }\end{array}$ & $\begin{array}{l}\text { Unbalance } \\
\text { VPP }\end{array}$ & $\lambda^{\mathrm{DR}}$ & $\mathrm{R}$ & $\lambda^{\mathrm{ISO}}$ & $\begin{array}{c}\text { Unbalance VPP } \\
\text { with DR }\end{array}$ \\
\hline 1 & $0.2 \%$ & $3.7 \%$ & $0.0 \%$ & $4.4 \%$ & $-0.5 \%$ & & & 149.0 & $-0.5 \%$ \\
\hline 2 & $0.0 \%$ & $4.6 \%$ & $0.0 \%$ & $3.6 \%$ & $1.0 \%$ & 116.9 & 131.9 & 129.0 & $0.0 \%$ \\
\hline 3 & $-12.7 \%$ & $3.9 \%$ & $0.0 \%$ & $-13.1 \%$ & $4.3 \%$ & 112.0 & 73.5 & 119.0 & $3.1 \%$ \\
\hline 4 & $2.4 \%$ & $2.2 \%$ & $0.0 \%$ & $4.1 \%$ & $0.6 \%$ & 107.0 & 21.3 & 109.0 & $0.1 \%$ \\
\hline 5 & $0.0 \%$ & $1.8 \%$ & $0.0 \%$ & $1.0 \%$ & $0.8 \%$ & 107.0 & 20.9 & 109.0 & $0.4 \%$ \\
\hline 6 & $-0.3 \%$ & $5.2 \%$ & $0.0 \%$ & $0.7 \%$ & $4.2 \%$ & 109.3 & 44.7 & 113.6 & $3.3 \%$ \\
\hline 7 & $1.3 \%$ & $4.9 \%$ & $0.0 \%$ & $3.1 \%$ & $3.1 \%$ & 116.9 & 131.7 & 129.0 & $0.7 \%$ \\
\hline 8 & $1.4 \%$ & $3.4 \%$ & $0.2 \%$ & $1.7 \%$ & $3.2 \%$ & 129.2 & 288.3 & 154.0 & $0.0 \%$ \\
\hline 9 & $0.3 \%$ & $5.0 \%$ & $0.5 \%$ & $-1.3 \%$ & $7.1 \%$ & 139.4 & 437.9 & 175.0 & $0.4 \%$ \\
\hline 10 & $-1.6 \%$ & $6.2 \%$ & $0.9 \%$ & $-3.7 \%$ & $9.2 \%$ & 141.3 & 463.7 & 179.0 & $2.3 \%$ \\
\hline 11 & $0.3 \%$ & $6.3 \%$ & $0.8 \%$ & $-0.8 \%$ & $8.2 \%$ & 141.3 & 479.1 & 179.0 & $1.1 \%$ \\
\hline 12 & $1.6 \%$ & $7.2 \%$ & $1.0 \%$ & $1.0 \%$ & $8.7 \%$ & 141.3 & 489.3 & 179.0 & $1.5 \%$ \\
\hline 13 & $-10.1 \%$ & $6.2 \%$ & $-0.4 \%$ & $-14.6 \%$ & $10.3 \%$ & 141.3 & 482.6 & 179.0 & $4.1 \%$ \\
\hline 14 & $3.8 \%$ & $6.8 \%$ & $-0.4 \%$ & $3.8 \%$ & $6.3 \%$ & 141.3 & 507.9 & 179.0 & $0.0 \%$ \\
\hline 15 & $-0.1 \%$ & $5.7 \%$ & $-1.1 \%$ & $-1.9 \%$ & $6.3 \%$ & 136.5 & 417.7 & 169.0 & $0.2 \%$ \\
\hline 16 & $1.6 \%$ & $5.1 \%$ & $-0.1 \%$ & $0.4 \%$ & $6.3 \%$ & 131.1 & 344 & 158.0 & $1.1 \%$ \\
\hline 17 & $-0.3 \%$ & $8.5 \%$ & $-0.4 \%$ & $-2.3 \%$ & $10.0 \%$ & 131.1 & 340.2 & 158.0 & $4.9 \%$ \\
\hline 18 & $0.2 \%$ & $10.6 \%$ & $-0.4 \%$ & $-1.2 \%$ & $11.5 \%$ & 136.5 & 408.5 & 169.0 & $5.4 \%$ \\
\hline 19 & $-0.3 \%$ & $10.5 \%$ & $-0.1 \%$ & $-1.5 \%$ & $11.7 \%$ & 136.5 & 403.2 & 169.0 & $5.5 \%$ \\
\hline 20 & $0.2 \%$ & $9.3 \%$ & $-0.2 \%$ & $-0.9 \%$ & $10.2 \%$ & 136.5 & 405.7 & 169.0 & $4.0 \%$ \\
\hline 21 & $5.7 \%$ & $10.3 \%$ & $0.0 \%$ & $6.3 \%$ & $9.8 \%$ & 136.5 & 441 & 169.0 & $3.2 \%$ \\
\hline 22 & $2.7 \%$ & $8.6 \%$ & $0.0 \%$ & $2.0 \%$ & $9.3 \%$ & 136.5 & 438.8 & 169.0 & $2.9 \%$ \\
\hline 23 & $-9.5 \%$ & $5.7 \%$ & $0.0 \%$ & $-14.3 \%$ & $10.6 \%$ & 129.2 & 321.3 & 154.0 & $6.5 \%$ \\
\hline 24 & $2.5 \%$ & $8.6 \%$ & $0.0 \%$ & $2.7 \%$ & $8.4 \%$ & 129.2 & 299.9 & 154.0 & $3.5 \%$ \\
\hline
\end{tabular}

TABLE IV

DR INFLUENCE ON FINANCIAL LOSSES FOR CASE STUDY \#2

\begin{tabular}{|c|c|c|c|c|c|c|c|c|c|c|c|}
\hline \multirow[t]{2}{*}{$\begin{array}{l}\text { Hourly } \\
\text { Interval }\end{array}$} & \multirow{2}{*}{$\begin{array}{c}\text { Unbalance } \\
\Delta \\
\text { witihout } \\
\text { DR } \\
{[\mathrm{MW}]}\end{array}$} & \multicolumn{2}{|c|}{$\begin{array}{l}\text { Unbalance Costs } \\
\text { [RON/MWh] }\end{array}$} & \multirow{2}{*}{$\begin{array}{c}\begin{array}{c}\text { Supplementary } \\
\text { Cost }\end{array} \\
{[\mathrm{RON}]} \\
\end{array}$} & \multicolumn{2}{|c|}{$\begin{array}{l}\text { Unbalance influence } \\
\text { without DR }\end{array}$} & \multirow{2}{*}{$\begin{array}{c}\text { Unbalance } \\
\Delta \text { with } \\
\text { DR } \\
{[\mathrm{RON}]}\end{array}$} & \multirow{2}{*}{$\begin{array}{c}\text { DR } \\
{[\mathrm{MW}]} \\
\end{array}$} & \multirow{2}{*}{$\begin{array}{c}\begin{array}{c}\text { Supplementary } \\
\text { Cost }\end{array} \\
{[\mathrm{RON}} \\
\end{array}$} & \multicolumn{2}{|c|}{$\begin{array}{c}\text { Unbalance influence } \\
\text { with DR }\end{array}$} \\
\hline & & Excess & Deficit & & [RON/MWh] & {$[\%]$} & & & & [RON/MWh] & {$[\%]$} \\
\hline 1 & 29.4 & 30 & 344 & 4369.5 & 32.74 & $16.8 \%$ & 29.38 & 0.00 & 4369.5 & 0.78 & $0.40 \%$ \\
\hline 2 & -51.4 & 34.26 & 356.78 & 7858.5 & 32.25 & $17.2 \%$ & 0.00 & -51.36 & 0.0 & 0.00 & $0.00 \%$ \\
\hline 3 & -262.5 & 75.79 & 394 & 24435.9 & 27.99 & $16.6 \%$ & -188.97 & -73.50 & 17593.0 & 2.90 & $1.72 \%$ \\
\hline 4 & -28.8 & 50.22 & 384 & 3448.8 & 41.21 & $24.2 \%$ & -7.50 & -21.30 & 897.7 & 0.18 & $0.10 \%$ \\
\hline 5 & -42.0 & 77.04 & 390 & 4026.3 & 40.32 & $23.3 \%$ & -21.10 & -20.90 & 2022.8 & 0.39 & $0.23 \%$ \\
\hline 6 & -217.3 & 67.4 & 390 & 26899.0 & 26.65 & $13.9 \%$ & -172.60 & -44.70 & 21365.6 & 4.12 & $2.16 \%$ \\
\hline 7 & -168.8 & 67.51 & 400 & 23682.3 & 29.36 & $14.1 \%$ & -37.11 & -131.70 & 5206.2 & 0.97 & $0.47 \%$ \\
\hline 8 & -187.2 & 78.1 & 431 & 30863.5 & 29.69 & $12.2 \%$ & 0.00 & -187.15 & 0.0 & 0.00 & $0.00 \%$ \\
\hline 9 & -460.8 & 30 & 407 & 101829.6 & 16.29 & $6.5 \%$ & -22.87 & -437.90 & 5053.7 & 0.78 & $0.31 \%$ \\
\hline 10 & -616.7 & 30 & 415 & 136285.6 & 9.73 & $3.9 \%$ & -152.98 & -463.70 & 33807.9 & 5.05 & $2.01 \%$ \\
\hline 11 & -551.8 & 30 & 413 & 118630.7 & 9.98 & $4.1 \%$ & -72.67 & -479.10 & 15624.2 & 2.33 & $0.95 \%$ \\
\hline 12 & -588.9 & 30 & 408 & 122490.1 & 6.82 & $2.9 \%$ & -99.59 & -489.30 & 20715.7 & 3.08 & $1.29 \%$ \\
\hline 13 & -806.7 & 30 & 400.28 & 169403.4 & 1.23 & $0.5 \%$ & -324.12 & -482.60 & 68062.2 & 8.67 & $3.61 \%$ \\
\hline 14 & -430.4 & 30 & 401 & 83920.1 & 9.66 & $4.3 \%$ & 0.00 & -430.36 & 0.0 & 0.00 & $0.00 \%$ \\
\hline 15 & -431.9 & 30 & 380 & 81626.1 & 6.66 & $3.0 \%$ & -14.18 & -417.70 & 2680.8 & 0.39 & $0.18 \%$ \\
\hline 16 & -415.7 & 30 & 382 & 73169.7 & 6.10 & $3.0 \%$ & -71.74 & -344.00 & 12625.7 & 1.91 & $0.93 \%$ \\
\hline 17 & -670.3 & 30 & 378 & 117976.4 & 2.42 & $1.2 \%$ & -330.12 & -340.20 & 58101.2 & 8.67 & $4.21 \%$ \\
\hline 18 & -764.0 & 30 & 381 & 148974.0 & 4.79 & $2.1 \%$ & -355.47 & -408.50 & 69316.5 & 10.48 & $4.66 \%$ \\
\hline 19 & -765.0 & 30 & 388 & 152235.1 & 1.42 & $0.6 \%$ & -361.80 & -403.20 & 71998.3 & 10.98 & $4.80 \%$ \\
\hline 20 & -669.6 & 30 & 399 & 140612.3 & 6.08 & $2.5 \%$ & -263.91 & -405.70 & 55419.3 & 8.46 & $3.52 \%$ \\
\hline 21 & -651.0 & 30 & 405 & 143865.5 & 8.57 & $3.4 \%$ & -209.98 & -441.00 & 46404.5 & 6.99 & $2.78 \%$ \\
\hline 22 & -636.8 & 30 & 413 & 140731.2 & 10.11 & $4.0 \%$ & -197.99 & -438.80 & 43756.4 & 6.36 & $2.53 \%$ \\
\hline 23 & -826.0 & 30 & 411 & 161060.4 & 2.92 & $1.3 \%$ & -504.65 & -321.30 & 98406.9 & 12.62 & $5.61 \%$ \\
\hline 24 & -512.9 & 30 & 333 & 92329.3 & 3.72 & $1.8 \%$ & -213.04 & -299.90 & 38347.3 & 6.31 & $3.01 \%$ \\
\hline
\end{tabular}


Regarding minimizing the financial losses, from Table 4 it can be seen very clearly that using DR reduces supplementary costs determined by acquiring or selling energy to the balancing market during unbalance hourly intervals. The economy is about 1418947.9 RON from 2110723.3 to 691775.4 RON.

\section{CONCLUSION}

Implementing the concept of VPP, determine the growth of power system benefits, due to using more efficient the distributed generation units, hence a greater operation efficiency. In this case, distributed generation can become more visible, can have a better access to energy markets and also can maximize the opportunities regarding incomes from selling the energy and reducing the environment pollution by using fewer classical power plants. The VPP can be considered an observable instrument for optimal solving of renewable energy sources integration and the case studies presented emphasize this aspect.

The results from the case studies prove that including the original elements in the VPP management - meaning considering the level of BVPP and the level of additional optimization by minimizing the financial losses due to acquiring energy from the balancing market, is justified and leads to better performance for the VPP.

Even more, it is again confirmed the fact that the VPP can be the favorable element in the power grid evolution towards "smart grid".

\section{REFERENCES}

[1] L. Nikonowicz, J. Milewski, (2012). Virtual Power Plants - general review: structure, application and optimization, Journal of Power Technologies. 92 (3), pp. 135-149.

[2] P. Andersen, B. Poulsen, M. Decker, C. Traeholt, J. Ostergaard, "Evaluation of a generic virtual power plant framework using service oriented architecture", $2^{\text {nd }}$ IEEE International Conference on Power Energy (PECon 08), Johor Baharu, Malaysia, December 1-3, 2008, pp. 1212-1217.

[3] G. Kaestle, "Virtual Power Plants as real CHP-clusters: a new approach to coordinate the feeding in the low voltage grid", $2^{\text {nd }}$ International Conference on Integration of Renewable and Distributed Energy Resources, Napa, CA, USA, 4-8 December, 2006.

[4] S. You, Developing Virtual Power Plant for optimized distributed energy resources operation and integration, $\mathrm{PhD}$. Thesis, Department of Electrical Engineering, Technical University of Denmark, September 2010.

[5] A. Mnatsakanyan, S. Kennedy, "Optimal demand response bidding and pricing mechanism: Application for a virtual power plant", $1^{\text {st }}$ IEEE Conference on Technologies for Sustainability (SusTech), Portland, OR, USA, $1-2$ august 2013, pp. 167-174,.

[6] L. Marcela, Virtual power plant management optimization OptiMaCEV, $\mathrm{PhD}$. thesis, Ed. Politehnica, Timisoara, Romania, 2015 (in romanian).

[7] R.A. Ahangar, A. Sheykholeslami (2014). Bulk Virtual Power Plant, a Novel Concept for Improving Frequency control and Stability in Presence of Large Scale RES, International Journal of Mechatronics, Electrical and Computer Technology, 4 (10), pp. 1017-1044.

[8] CNTEE Transelectrica S.A., Romanian Trasmission System Operator, Productie, Consum, Sold. Available: http://www.transelectrica.ro

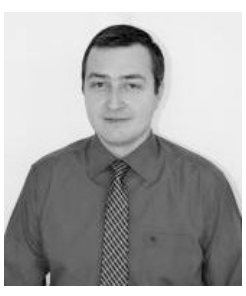

Dan Jigoria-Oprea (M'08) was born in Caransebes, Romania on the $31^{\text {st }}$ of October 1983. He received the B.S. (2007) and PhD. (2010) in power systems engineering from Politehnica University Timisoara, Romania.

From 2007 to 2010 he was a PhD. Student and Research Assistant at the Power Systems Department of Politehnica University Timisoara. From 2010 to 2012 was a Teaching Assistant and since 2012 is an Assistant Professor/Lecturer at the Power Systems Department of Politehnica University Timisoara. He is the author of over 45 articles, 5 books and member in 10 research contracts. His research interests include power systems optimization and operation, renewable energy sources integration and energy market.

Mr Jigoria-Oprea is also a member of SIER, the Romanian Society of Power Systems Engineers.

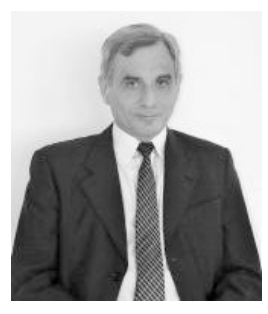

Gheorghe Vuc (M'05) was born in Timisoara, Romania, in 1958. He received the B.S. (1984) and the Ph.D. degree (1998) in power systems engineering from Politehnica University Timisoara, Romania.

From 1984 to 1990 he was operational engineer at Romanian TSO

(Transelectrica).

From 1990 to 1998 he was a PhD. Student and Assistant Professor at the Power Systems Department of Politehnica University Timisoara. From 1998 to 2006 was a Lecturer and since 2006 is an Associate Professor at the Power Systems Department of Politehnica University Timisoara. He is the author of over 68 articles, 4 books and member in 12 research contracts. His research interests include power systems optimization and operation, renewable energy sources integration and energy market.

Mr. Vuc is also a member of SIER, the Romanian Society of Power Systems Engineers.

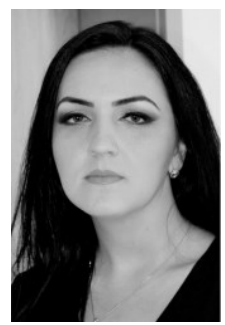

Marcela Litcanu was born in Otelu Rosu, Romania on the $30^{\text {th }}$ September 1986 , received the $\mathrm{PhD}$. in power systems engineering from Politehnica University Timisoara, Romania, in 2015. Previously, she recieved a bachelor and master degree in Engineering and Management from Faculty Of Management In Production And Transportation, at Politehnica University of

Timisoara.

From 2011 to 2015, he was a Research Assistant and PhD. Student with the Power Systems Department at Politehnica University of Timisoara. Currently, she is with QMB Energy SRL from Timisoara, Romania. She is an author of 8 articles. Her research interest includes energy market and power system operation. 